\title{
Corrosion Inhibition of Mild Steel in Hydrochloric Acid using4- (pyridin-2yl)-N-p-tolylpiperazine-1-carboxamide
}

\author{
Sumathi Paramasivam ${ }^{1, *}$, Kannan Kulanthai ${ }^{2}$, Gnanavel Sadhasivam ${ }^{2}$, Rekha Subramani ${ }^{1}$ \\ ${ }^{1}$ Department of Chemistry, Knowledge Institute of Technology, Salem, Tamilnadu, India. \\ ${ }^{2}$ Department of Chemistry, Government College of Engineering, Salem, Tamilnadu, India \\ *E-mail: sumathi.murugan25@gmail.com
}

doi: $10.20964 / 10109$

Received: 8 July 2015 / Accepted: 16 February 2016 / Published: 1 April 2016

4-(pyridin-2yl)-N-p-tolylpiperazine-1-carboxamide(PTC) was synthesized and characterized using FTIR, ${ }^{1} \mathrm{H}$ NMR, and ${ }^{13} \mathrm{C}$ NMR spectra. The inhibitive action of 4-(pyridin-2yl)-N-p-tolylpiperazine-1carboxamide(PTC) against corrosion of mild steel in a $1 \mathrm{M} \mathrm{HCl}$ solution was investigated using weight loss measurements, potentiodynamic polarization and electrochemical impedance spectroscopy(EIS). The inhibition efficiency increases with increasing concentration of inhibitor whereas it decreases with increasing temperature. EIS results showed that the change in the impedance parameters (Rct and Cdl) with concentration of (PTC) is indicative of the adsorption of molecules leading to the formation of a protective layer on the surface of mild steel. Potentiodynamic polarization study showed that PTC is a mixed type inhibitor. Surface analysis by SEM confirmed the formation of adsorbed protective layer of the inhibitor on the steel surface. The adsorption of inhibitor follows the Langmuir adsorption isotherms. Thermodynamic parameters such as activation energy (Ea), free energy change ( $\Delta \mathrm{Gads})$, enthalpy change $(\Delta$ Hads $)$ and entropy change ( $\Delta$ Sads $)$ were also calculated and discussed in detail.

Keywords: Corrosion; Inhibition efficiency: $\mathrm{HCl}$, Mild steel, Weight loss, EIS, Tafel Polarization and adsorption.

\section{$\underline{\text { FULL TEXT }}$}

(C) 2016 The Authors. Published by ESG (www.electrochemsci.org). This article is an open access article distributed under the terms and conditions of the Creative Commons Attribution license (http://creativecommons.org/licenses/by/4.0/). 